\title{
La penetración del neoliberalismo en los ámbitos subnacionales. El caso Córdoba: análisis de las leyes provinciales del Estado nuevo y el Pacto fiscal ${ }^{*}$
}

The penetration of neoliberalism in the sub-national levels. The Cordoba case: analysis of new State's provincial laws and the Fiscal Pact

Recibido: 16 de julio de 2011 - Revisado: 06 de agosto de 2011 - Aceptado: 02 de septiembre de 2011

Alejandro Gabriel Manzo**

\section{Resumen}

Este artículo tiene por objetivo analizar las estrategias de difusión-imposición y el contenido del neoliberalismo en las provincias y municipios de Argentina tomando como marco de referencia el caso Córdoba. A tal fin se divide en dos grandes partes: una primera, en la cual se presentan una serie de categorías analíticas destinadas a mostrar las estrategias que los agentes centrales utilizan a la hora de difundir-imponer el neoliberalismo en la era de la globalización y los rasgos sobresalientes de las reformas neoliberales de primera y segunda generación. La segunda, en la que se realiza un análisis socio-histórico del campo político cordobés y jurídico-dogmático de las normas a través de las cuales se dio forma al proyecto del Estado nuevo y al Pacto fiscal del año 2000.

Palabras clave

Neoliberalismo, reforma del Estado, Bancos Multilaterales de Desarrollo, ámbitos subnacionales.

\begin{abstract}
The objective of this article is to analyze the strategies of difusion/imposition and the content of the neoliberalism in the provinces and municipalities of Argentina using the "Córdoba's case" as a case of reference. It is divided in two main parts: the first one, presents the strategies that the central agents use to spread/impose the neoliberalism in different parts of the planet and the main features of the neoliberal reforms of first and second generation; the second one, makes an historical analysis of the political field of Córdoba and a juridical analysis of the norms that gave form to the process of the "New State" and the "Fiscal Pact" of 2000.
\end{abstract}

\section{Key words}

Neoliberalism, State reform, multilateral development banks, sub-national levels.

\footnotetext{
"El artículo presenta resultados de investigación provenientes de la tesis doctoral "Derecho e Institucionalización del Neoliberalismo en Argentina": las reformas legales del período 1976-2002, presentada a la Facultad de Derecho y Ciencias Sociales de la Universidad Nacional de Córdoba (UNC) y cofinanciada por el Consejo Nacional de Ciencia y Tecnología (CONICET) y el Ministerio de Ciencia y Tecnología de Córdoba, Argentina.

${ }^{* *}$ Magíster del Instituto Internacional de Sociología Jurídica, Oñati, España. Investigador Universidad Nacional de Córdoba, Argentina.

Correo electrónico:

alemanzzo@hotmail.com.
} 


\section{Introducción}

A finales del siglo XX el neoliberalismo era fuertemente cuestionado desde distintos sectores. El moderno proceso de globalización neoliberal activado en la década de los setenta, explica Rapoport (2010, p. 466), había dado lugar a una economía "virtual" en la que proliferaron las prácticas especulativas, las burbujas y la corrupción financiera. La crisis "tequila" de 1994, la "de los tigres asiáticos" de 1997, la "de Rusia" de 1998 y la "de Brasil" de 1999 habían llevado al extremo la inestabilidad de los mercados emergentes. Finalmente, distintos indicadores oficiales mostraban un acelerado aumento de la inequidad en la distribución de los recursos sociales, de la pobreza y el desempleo, al mismo tiempo que exhibían una clara desaceleración del ritmo de crecimiento de la economía mundial con respecto a décadas anteriores.

Bajo esta performance, los "Bancos Multilaterales de Desarrollo" (BMD) se encontraban bajo ataque tanto por los presupuestos desde los que habían partido para afrontar las crisis mencionadas como por su dilatada injerencia en cuestiones que hasta entonces se consideraban resguardadas por la soberanía de sus Estados miembros ${ }^{1}$. Estos ataques provenían no solo de los críticos del neoliberalismo (v. gr. "heterodoxos") sino también, paradójicamente, de sus propios promotores (v. gr. "ortodoxos" o "neoconservadores"). Desde su lógica, expuesta por la Comisión Meltzer del año 2000², la intervención "planificada" del Fondo en las crisis financieras iba en contra de los principios del libre mercado y favorecía la actuación de los capitales especulativos y de aquellos gobiernos que menospreciaban los riesgos financieros (v. gr. morald hazard).

Argentina no estaba ajena a estos fenómenos. Hacia 1999, las principales fuentes de financiamiento del "régimen de convertibilidad" se hallaban en serias dificultades ${ }^{3}$. La tasa de crecimiento del PBI había caído del $8,11 \%$ al $3,85 \%$ y al $-3,39 \%$ en 1997,1998 y 1999 , res- pectivamente. La balanza comercial que había sido positiva en 1760 millones de dólares en 1996, fue en los dos años subsiguientes deficitaria por un monto de 2123 y 3117 millones. La deuda externa, que a 1992 era de 62.586 millones de dólares, alcanzó los $145.430 \mathrm{mi}-$ llones en 1999. Las cuentas públicas se habían desordenado con motivos de las elecciones. Las tasas de desempleo-subempleo (que llegó por entonces al $30 \%$ de la PEA) y de la población pobre-indigente (que superó el $35 \%$ del total de habitantes) habían sido el marco para el surgimiento de nuevos agentes sociales (v. gr. piqueteros, CTA, MTA, etcétera) que clamaban por un cambio de modelo.

Paradójicamente, en este contexto Córdoba inició un extendido proceso de reforma estatal institucionalizado por las leyes 8.835/6/7 y 8.864 , y en consonancia con los presupuestos propios del neoliberalismo. ¿Cómo y por qué sucedió esto?, o más concretamente, ¿cuáles fueron los estrategias utilizadas por los agentes centrales para difundir-imponer el neoliberalismo en Córdoba y qué contenido particular adquirió esta doctrina económica-social en esta provincia?

\section{Estrategias de difusión-imposición del neoliberalismo: las reformas de primera y segunda generación}

El análisis de la difusión-imposición de reformas institucionales propicias para el desenvolvimiento del capitalismo ha cobrado en los últimos años relativa importancia dentro de la teoría social. Dicha importancia, sin embargo, no se ha manifestado con igual intensidad en los ámbitos subnacionales de aquellos Estados organizados a través de un sistema federal de gobierno (Lardone, 2006).

En estos ámbitos, a diferencia de lo que ocurre a nivel nacional, dos son los agentes centrales impulsores de esta doctrina económicasocial: "los BMD" y "una instancia de gobierno superior (nación o provincia según el caso) 
que previamente ha adherido a los postulados del neoliberalismo". Entre las estrategias que a estos efectos utilizan los primeros, resaltan "los créditos por condicionalidades" (es decir, créditos que se otorgan a un gobierno bajo condición de cumplimiento de una serie de políticas de reforma estatal) y el papel de los think tanks como máxima expresión de un conjunto de mecanismos destinados a controlar, intervenir y definir la realidad a través de un marco de referencia afín al paradigma que se procura implementar.

Al igual que sucede con los $\mathrm{BMD}$, las relaciones entre las autoridades de una instancia de gobierno superior con aquellas otras de una instancia inferior pueden adquirir carácter eminentemente "cooperativo" o "coercitivo". En el primer caso, la provincia o municipio adhiere de manera voluntaria a un proceso de reforma instado desde el ámbito nacional, en tanto que en el segundo lo hace en función de las presiones que de este último recibe. Estas presiones se materializan a partir del uso estratégico de recursos políticos o económicos que la instancia superior pone a disposición o retira de la inferior y que esta, con mayor o menor premura, necesita.

Es fundamental advertir que desde principios de los noventa las provincias-municipios del territorio constituyeron espacios de creciente atención de los BMD y teniendo en cuenta que, en virtud de los procesos de descentralización que ellos mismos promovieron, estos manejaban alrededor de la mitad del total del gasto público argentino (Takagi, 2004, p. 46). El control del gasto, centro de sus programas desde los años ochenta, adquirió en Argentina especial significación en razón de las particulares características del régimen de convertibilidad que obligaba a mantener un ahorro lo suficientemente elevado como para financiar la paridad cambiaria establecida (un dólar igual a un peso). Tras la crisis tequila de 1994, esta atención lejos de decrecer se incrementó y a medida que la situación económica se deterioró, cada uno de los acuerdos firmados por las autoridades nacionales con las del FMI incluyeron condicionalidades dirigidas a los ámbitos subnacionales.

Esta situación motivó el diseño de una nueva estrategia crediticia en virtud de la cual los BMD contrataron directamente - esto es, saltando la jurisdicción nacional- con la esfera provincial. Hasta finales de los noventa, el procedimiento de contratación se realizaba con el gobierno federal ${ }^{4}$. Se trataba de un proceso complejo y de varias instancias en el que la relación con los BMD se encauzaba principalmente a través del Ministerio de Economía y de la jefatura de gabinete. Durante el período de negociación, las provincias presentaban sus programas a estos organismos con la pretensión de ser incluidas en el marco del contrato general (CAS) y en el pliego anual de reformas (pipeline). Aprobado el crédito, el dinero desembolsado se entregaba a la nación y ella era quien lo distribuía entre las distintas gobernaciones. Se aseguraba de este modo un riguroso control de la economía de los BMD por sobre el gobierno federal y, de este último, por sobre las provincias. Tal como lo mostraron los informes en la segunda mitad de los noventa, la lentitud que este procedimiento suponía, se erigía como una cuestión cada vez más preocupante para estas instituciones.

La decisión de contratar directamente con las provincias "grandes" (v. gr. Buenos Aires, Córdoba y Santa $\mathrm{Fe}$ ) no anuló, sin embargo, el papel del Estado nacional. Ya sea como garante en el caso del BID o como prestatario formal en el del BM (PRL-SNAL), este último se aseguraba un rol preponderante en el proceso de contratación garantizándose un instrumento político de cambio de enorme peso. Este instrumento era complementario de los denominados "Pactos fiscales". Estos eran acuerdos en virtud de los cuales los gobernadores aceptaban efectuar un conjunto de transformaciones estatales en consonancia con los presupuestos propios del neoliberalismo a cambio del envío de un flujo de divisas ya sea en concepto de coparticipación o 
inclusión dentro de programas nacionales de obras o servicios públicos, de industrialización, etcétera.

Las crisis de mediados de la década de los noventa se manifestaron también en un cambio en el contenido del recetario de políticas neoliberales con destino a América Latina. Hasta entonces este estaba definido por el consenso de Washington de 1989. Sus principales premisas eran la monetarización del mercado, la apertura de la economía local a la internacional, la descentralización del aparato estatal, la privatización de sus empresas, la flexibilización y desrregularización del trabajo. El principio inmanente del "crecimiento económico", objetivo central del neoliberalismo, se encontraba fuera del Estado en la inversión privada.

La base analítica de esta generación de reformas estaba dada por las teorías que se asientan en los presupuestos propios del homo económicus ${ }^{5}$. El mercado aparece como un principio de asignación de recursos autorregulado que tiende por su propia lógica interna hacia el equilibrio. Son los agentes privados los que a partir del libre juego de la oferta y de la demanda producen crecimiento y de allí, el progreso de todas las clases sociales (v. gr. teoría del derrame). Se trata de concepciones atomistas, abstractas, en las que el poder se halla diluido entre todos los miembros del universo social.

Bajo estos presupuestos el Estado, como entidad autónoma, desaparece. En realidad, lo que desaparece es la sociedad toda; todo nivel agregado carece de autonomía en la medida en que todo comportamiento colectivo o macro puede, desde esta concepción, reducirse en último término a comportamientos individuales o micros (March y Olsen, 1993, p. 6). Sousa Santos (2005, p. 312 y ss) explica que durante esta generación el Estado se concibe como "irreformable". Desde esta posición "anti-estatista" la única solución posible para el progreso de la sociedad, que es el mercado, es su erradicación. La primera oleada de reformas impulsadas por los BMD estuvo destinada a desmantelar el Estado de Bienestar en aras a la penetración del nuevo modo de acumulación. Como bien señalan Lardone y Donadi (2007, p. 9), durante los noventa las transformaciones neoliberales en Argentina "han logrado desmantelar el viejo Estado, pero no han logrado construir una administración pública capaz y eficiente...".

Las crisis de los mercados emergentes fueron acompañadas por una profunda autocrítica por parte de los BMD cuyo punto álgido estuvo representado por el informe del BM sobre el Desarrollo Mundial de 1997. Este marcó la emergencia de un "posconsenso de Washington" sustentado en las "teorías del neo institucionalismo". En estas, cuyo desenvolvimiento en el plano académico puede entenderse precisamente en términos de una reacción frente a las teorías del actor racional, el nivel institucional adquiere carácter autónomo de otros niveles de análisis. El Estado concebido como "institución" recupera su autonomía; se convierte en un "Estado Reformable" en términos de Sousa Santos (2005, p. 312). Un "entramado institucional" eficiente, que supone entre otras cuestiones la vuelta a lo público y a la sociedad civil, es un requisito sine qua non para producir un "desarrollo económico sustentable". Los créditos del BM y del BID se dirigen en este sentido e incluyen, también, propuestas propias de las teorías del New Public Managment que procuran la importación de principios gerenciales privados a la administración pública? ${ }^{7}$.

El paso del "consenso" al "posconsenso" de Washington también se manifestó en un cambio en la noción de democracia. En la primera generación de reformas esta noción se diluyó y subordinó a otros dos conceptos: "el de la gobernabilidad" y "el del principio del mercado". En efecto, la función principal del régimen político era para los BMD la de generar las condiciones de estabilidad y seguridad necesarias (v. gr. gobernabilidad) para la atracción de inversiones privadas, generalmente de origen extranjero. En América Latina esto se materia- 
lizó en las dictaduras militares de los años setenta y ochenta y en la puesta en práctica de una democracia "mínima y formal" en los noventa (Burgos, 2000).

Sousa Santos (2007, p. 30 y ss), quien ha realizado una genealogía sobre la temática, retro trae estos conceptos hasta la crisis del Estado de Bienestar en la década de los setenta y establece una polarización entre dos perspectivas rivales. Mientras que la teoría de la "crisis de legitimidad" — de raíz habermasiana - cuestionaba radicalmente el contrato social de los Estados de la posguerra tanto en su contenido social (extremadamente excluyente) como en su carácter democrático (escasamente participativo), la de la "gobernabilidad" postulaba exactamente lo contrario: el modelo estaba en aprietos "pero no porque hubiera poca democracia, sino porque había demasiada. La democracia estaba en crisis porque había una sobresaturación de derechos y reclamos, porque el contrato social en vez de ser demasiado excluyente era demasiado inclusivo...". El informe de la comisión trilateral de 1975 estableció la terapia que debía aplicarse para superarla: "Privatización, liberalización y marketización”.

En la segunda generación de reformas, la noción de 'democracia' se vio redefinida de conformidad a una nueva narrativa. La "gobernanza neo-liberal" apareció, en efecto, como la síntesis superadora entre ambas teorías rivales durante las décadas pasadas: "la gobernanza busca armonizar las reivindicaciones a favor de la participación y la inclusión (crisis de legitimidad) con las exigencias de una mayor autonomía y autorregulación (crisis de gobernabilidad)... (Sousa Santos, 2007, p. 34)". La gobernanza, advierte Cáceres (2006, p. 167), "se presenta como un nuevo estilo de gobierno que pretende superar los fracasos de otros modos de coordinación como la mano invisible del mercado o la planificación top-down del Estado de Bienestar...". ¿Como pretende superarlo? A partir de "redes" flexibles de "cooperación" entre los distintos sujetos involucrados en una política pública (rompe con ello con la planificación top down). En los enfoques del neo-institucionalismo, el panorama se completó con los denominados "dilemas de la acción colectiva" (Rothstein, 2001, p. 213) destinados a generar entramados institucionales que asegurasen la cooperación sobre problemas comunes entre agentes con intereses divergentes y hasta contradictorios entre sí (se quiebra con ello con la lógica individualista del actor racional).

En este artículo, y tal como lo vemos a continuación, abordamos estas dimensiones teóricas a partir de un análisis, por un lado, socio-histórico del campo político cordobés dirigido a advertir cómo estas estrategias de difusión-imposición operaron en el caso concreto, y por otro, jurídico-normativo destinado a mostrar el contenido del recetario neoliberal de los BMD en el marco de una reforma estatal en particular.

\section{La reforma del Estado antes de la crisis tequila: "Córdoba, la isla nacional"}

Hasta el año 1995, Córdoba representó primero "la avanzada" y luego "la retaguardia" del país en lo que a los procesos de reformas del Estado se refiere. La razón principal de este fenómeno debe buscarse en la "lógica política partidaria”. En efecto, Córdoba se convirtió desde finales de los ochenta y durante toda la década de los noventa en el principal bastión del partido radical (UCR) en una Argentina cuasi monopolizada por el justicialismo (PJ). Fue precisamente este carácter el que le permitió, primero, introducir aquellas transformaciones exhortadas por el presidente Alfonsín a nivel nacional pero nunca efectivamente instauradas ("vanguardia") y, luego, resistir aquellas otras promovidas por el menemismo en los ámbitos subnacionales ("retaguardia").

Desde el advenimiento de la democracia en 1983, Córdoba fue gobernada por el radicalismo. Hacia 1985, el gobernador Angeloz, 
amparado en un contundente triunfo en los comicios legislativos, decidió instar un proceso de reforma de la constitución provincial (CPC) que lo habilitase a postularse para un nuevo mandato. Se inició a partir de entonces un intricado proceso de captación de los sufragios necesarios para activar dicho proceso. Así se consiguió utilizando las divisiones existentes en el interior del PJ (que poco tiempo después debió ser intervenido) y obteniendo el apoyo del "peronismo renovador" liderado por De la Sota.

Si bien, y como ya se advirtió, la reforma tenía un objetivo político inmediato, su alcance fue mucho más vasto y se completó con la modificación de la Ley Orgánica Municipal (LOM, n. $\left.{ }^{\circ} 8.102\right)$. Muchas de las transformaciones allí incluidas fueron receptadas luego por el resto de las gobernaciones provinciales y, en última instancia, por la Constitución Nacional (CN) en 1994.

Su contenido se encontró en términos generales en consonancia con el proceso de democratización activado a nivel federal por el doctor Alfonsín, aunque con un fuerte componente federalista. En un mayor grado de abstracción, se observa la influencia de los discursos neoliberales del "municipalismo" (v. gr. minimización del Estado vía descentralización) promovidos por entonces por los BMD a escala global. Sin embargo, debe resaltarse que estos no participaron en la construcción de la reforma y que los agentes locales, principalmente desde la Universidad Nacional de Córdoba, reinterpretaron estos discursos de conformidad a su propia racionalidad e intereses.

El "federalismo" fue materializado fundamentalmente a través del régimen de la autonomía municipal. Estos instrumentos legales lo reconocieron constitucionalmente, lo definieron y ampliaron en su faz política, administrativa, económica, financiera e institucional (ídem, art. $123 \mathrm{CN}$ ). Su grado fue categorizado a través de tres niveles institucionales; aparecían con competencias decrecientes: las ciudades, los municipios y las comunas según tuviesen, respecti- vamente, más de 10.000 habitantes, de 10.000 a 2000 habitantes o menos de 2000 habitantes. Las primeras eran las únicas capaces de dictarse sus propias "Cartas Orgánicas Municipales" en tanto que las otras dos se regirían, precisamente, por la LOM. La figura del "interventor comunal" fue reemplazada por las del "jefe" y "secretario" de comuna, elegidos directamente por las poblaciones locales (art. 1 y 2 LOM). La "democratización de la democracia" se completó con los denominados institutos de participación directa (v. gr. consulta popular).

El espíritu de la reforma puede ejemplificarse a través de dos políticas públicas que estas reformas activaron y que han sido analizadas empíricamente por múltiples trabajos de investigación ${ }^{8}$. Hasta el año 1995, "la descentralización" de funciones y competencias desde el nivel provincial al local — v. gr. en el área salud - era fruto de un proceso paulatino en el que ambas esferas de gobierno acordaban entre sí el modo y el tiempo de traspaso de las mismas. La "regionalización", por su parte, era una política estatal dejada en manos de los propios municipios y comunas que decidiesen agruparse con el fin de solucionar problemáticas comunes - art. 190 CPC y 183 LOM-. Se trató en ambos casos de procesos "desde abajo" con un fuerte respeto al principio de la autonomía; y tal vez por ello mismo, excesivamente lentos y graduales. El municipio era asociado sin más a conceptos tales como "la transparencia", "la eficiencia" y "la eficacia" de lo público.

En 1987, Mestre fue reelecto como intendente de Córdoba en tanto que la fórmula radical Angeloz-Negri triunfó sobre la justicialista De la Sota-Gastaldi $(49,09 \%$ vs. $44,45 \%$, respectivamente) $)^{9}$; situación que solo se repitió a nivel nacional en la provincia de Río Negro. Angeloz emergió, así, como el principal referente del partido en el país y fue derrotado en los comicios presidenciales por Menem-Duhalde en 1989. A partir de allí, Córdoba optó por una política de diferenciación del modelo menemista que le valió el calificativo popular de "la isla". 
En un principio, los avances de este modelo en los ámbitos subnacionales fueron prácticamente nulos. Los pactos fiscales I y II de 1992 y 1993 fueron los instrumentos legales escogidos para revertir esta situación. La fecha no es azarosa al coincidir con la entrega de los primeros créditos de los BMD al país. Los programas del BM "provincias I y II", base de los aludidos pactos, preveían el cumplimiento de una serie de medidas tendientes a difundir el neoliberalismo, en particular en lo referente a la modernización de los sistemas presupuestarios, la privatización de las empresas y de la banca pública, la descentralización de las entidades provinciales, la desregularización de sus economías, la transferencia a jurisdicción nacional de las cajas de jubilaciones, la reducción del número de empleados públicos y otras políticas destinadas a la disminución de los déficits presupuestarios provinciales (Lardone, 2006).

A contramano del resto, el gobierno cordobés se opuso a muchas de estas medidas. De hecho la provincia no suscribió los mencionados pactos, ni aceptó efectuar la transferencia a la nación de la caja de jubilaciones, no privatizó sus empresas ni los bancos provinciales. La relación entre la nación y la provincia adquirió de este modo un carácter ciertamente confrontativo que iba a terminar con la renuncia anticipada del gobernador Angeloz en 1995. A fin de entender las causas de este desenlace, es necesario retrotraerse a 1991.

Como ya se advirtió, la reforma constitucional de 1987 habilitó la reelección del gobernador pero lo hizo por solo un período más. Finalizado el mandato 1987-1991, Angeloz debía abandonar su cargo. Sin embargo, la corriente hegemónica del partido efectuó una "descarada" —en términos de Muñoz $(2007,5)$ - interpretación de la carta magna provincial que abrió la posibilidad de un tercer período. Los dos líderes de la UCR, Angeloz y Mestre, se enfrentaron en comicios internos en 1990. Ganador, el primero conservó su estatus al vencer por segunda vez a De la Sota en las elecciones de 1991 (UCR 52,03\% vs. PJ 36,49\%) ${ }^{10}$; per- dedor, el segundo se alejó interinamente de la política. La intendencia capitalina quedó en manos de otro radical, Rubén A. Martí.

La corrupción y el desprestigio inundaron la gobernación. Hacia mediados de la década, la situación de las finanzas provinciales era ciertamente preocupante. Desde principios de los noventa, el déficit fiscal en el que Córdoba sistemáticamente incurría se venía financiando a partir del uso ilegal de las reservas de los bancos públicos. La no suscripción de los Pactos Fiscales llevó aparejada la pérdida de un importante flujo de divisas destinado a la implementación de las aludidas reformas, en especial de aquellas provenientes de los BMD. Desde la nación se jugó con los plazos y montos de la coparticipación federal que correspondían a Córdoba. Contribuyó en este sentido, además de las disputas Menem-Angeloz, la ambición personal del ministro Cavallo de continuar su carrera política en la gobernación de la provincia de donde era originario ${ }^{11}$.

En este contexto, la crisis tequila tuvo un efecto demoledor. La intensidad de su repercusión debe entenderse principalmente a partir de la fuerte vinculación de la economía cordobesa con la brasileña; en especial con la retracción de la demanda automotriz proveniente de dicho país. En efecto, el PGB provincial que se había incrementado 6,98\% de 1993 a 1994 fue 5,11\% negativo de 1994 a 1995 . Se trató de una caída que casi duplicó a la acaecida en el nivel federal ${ }^{12}$.

Angeloz pidió el desembolso de los fondos de la coparticipación; solicitud que le fue denegada. La imposibilidad del gobierno de pagar los sueldos a los empleados públicos en tiempo y forma fue el detonante de la protesta social. En medio de violentas manifestaciones, con quema de edificios públicos (entre ellos el de la histórica sede del partido radical), Angeloz abandonó anticipadamente su tercer período de gobierno en manos del gobernador electo Ramón Mestre. Se iniciaba así una nueva etapa en lo que a la penetración del neoliberalismo en Córdoba se refiere. 


\section{La crisis tequila y la "capitulación" cordobesa}

La "capitulación" del gobierno cordobés con el menemismo se realizó en 1995. En ese año, el radicalismo abandonó parcialmente su posición ideológica precedente y adhirió a algunas de las reformas neoliberales que desde la presidencia se venían instando. Las presiones dirigidas a producir este resultado provinieron desde dos direcciones interrelacionadas: por un lado, de los BMD y por otro, desde el PE nacional. La base material de dicha presión, y en último término su efectividad, devino del envío de fondos a cambio de "condicionalidades".

Mestre debía conducir la provincia en tiempos tormentosos. Adoptó dos medidas de emergencia para afrontar la situación: suscribió los pactos fiscales y convocó a una misión del BM. La primera se realizó a cambio de un crédito de 70 millones de dólares que el gobierno nacional le envió a Mestre el día antes de su asunción y la remisión de los fondos adeudados de la coparticipación.

La segunda llegó a Córdoba en 1995 y presentó en diciembre un detallado informe sobre la situación económica de la provincia que incluía, además, las recetas neoliberales que debían adoptarse como requisito sine qua non para acceder a su financiamiento. El núcleo duro de estas estaba representado por un profundo ajuste del gasto público, la descentralización y privatización del Estado provincial y una reforma tributaria destinada a controlar el déficit presupuestario.

El equipo del gobernador no aceptó los términos y dejó sin efecto práctico esta última medida. Lardone (2006, pp. 82-83), quien ha realizado una reconstrucción histórica del proceso de negociación entre el gobierno y el BM advierte que esto sucedió por dos razones: por un lado, no hubo acuerdo sobre las privatizaciones requeridas y por otro, muchas de las medidas propuestas por esta institución ya habían sido puestas en marcha por Mestre aun antes del mencionado informe.

En efecto, el primer día de mandato el PE había enviado a la legislatura un plan de emergencia que fue efectivamente convertido en ley provincial n. ${ }^{\circ} 8.472$. Se trató de un plan que combinó medidas ortodoxas y heterodoxas. Entre las primeras, sobresalieron un recorte de los salarios de los empleados públicos y una reducción de las horas extras laborables. El personal debía trabajar en turnos rotativos. Se disminuyó asimismo la planta estatal. Se eliminaron cinco de los diez ministerios de la gobernación existentes, la mayoría de los cargos de asesores y un número significativo de empleados contratados. Se excluyeron exenciones tributarias y se aumentaron las alícuotas impositivas a fin de combatir la evasión. Entre las segundas, y en contra de las prescripciones del BM, se destacó la emisión de "bonos CECOR" por un monto cercano de 800 millones de pesos que circularon en la práctica cotidiana como moneda autorizada.

A estas medidas se sumaron otras de carácter estructural. Entre ellas sobresalieron la concesión a manos privadas de la prestación del servicio de agua potable y la sanción de la ley federal de educación, que desató una férrea oposición de los docentes provinciales (v. gr. UEPC). A esta se sumó la del sindicato de empleados públicos (SEP) en virtud de los ajustes realizados.

Es relevante destacar que el equipo del gobernador decidió mantener en la esfera pública las principales empresas estatales y no transferir a la nación la caja de jubilaciones. También contradiciendo las prescripciones privatistas de los BMD, activó un proceso de saneamiento y fusión de los bancos provinciales (Banco de Córdoba y Banco Social) en una sola entidad. La recuperación económica se produjo, finalmente, sin aumentar la deuda pública de Córdoba.

La oposición al oficialismo se completó con la de los intendentes y jefes comunales. En efecto, la llegada de Mestre a la "casa de las 
tejas" alteró de un momento a otro el equilibrio de poder existente entre el gobierno provincial y los locales. Si bien la relación entre el gobernador y el intendente de la ciudad capital Martí - fue positiva, no sucedió lo mismo en el interior cordobés. El núcleo del conflicto debe buscarse en el modo a partir del cual condujo la descentralización.

Tal como se mencionó, durante el mandato de su antecesor los tiempos del proceso estuvieron manejados, prioritariamente, por el nivel municipal-comunal. La crisis del 95 cambió considerablemente dicha situación. A fin de reducir el gasto público, Mestre literalmente se desprendió de competencias provinciales y se las cargó a la esfera local. Se trató de un proceso no necesariamente coordinado, especialmente en lo relativo a la remisión de fondos. Sobre muchos de los ejecutivos municipales recayó la responsabilidad de recortes salariales, sueldos adeudados, una deficiente prestación de servicios públicos y un creciente endeudamiento de las finanzas locales ${ }^{13}$.

Aun en la mayoría de los casos gobernadas por representantes de la UCR, las poderosas localidades del sur cordobés resistieron y se opusieron a dicha situación. Esta se vio agravada frente al creciente descuido del gobernador de los intereses agrícola-ganaderos de la región e hizo eclosión definitiva ante su tímida reacción frente a la emergencia ambiental de los años 1997 y 1998. El descontento llegó a tal punto que sectores interesados abogaron por una segregación provincial de la región con capital en Río IV. Estas medidas socavaron rápidamente la base electoral del partido radical y le costaron, en definitiva, la elección provincial de 1998.

\section{La hegemonía neoliberal en Córdoba: el proceso político de gestación del Estado nuevo y del Pacto fiscal}

Paradójicamente, el neoliberalismo devino en hegemónico en Córdoba en un momento en el cual ya no existía el acuerdo cuasi mono- lítico de mediados de la década de los noventa. Asimismo, debe observarse que este discurso penetró en el territorio cordobés a fines del siglo XX sin que existiese de por medio un endeudamiento relevante de la provincia ni una situación económica crítica que sirviese de escenario para ese cometido. Tampoco hubo un proceso de imposición de los BMD ni un entrecruzamiento entre la ideología tradicional del PJ local y el programa de transformaciones estatales que se activaron en 1999 - 2000. ¿Cómo, por lo tanto, se produjo este fenómeno?

La respuesta a este interrogante debe buscarse en la manera en la cual De la Sota y Kammerath llegaron a la gobernación y a la intendencia de la ciudad capital, respectivamente. Se trató, en efecto, de una adhesión voluntaria del PJ cordobés, en general, y de su máximo referente, en particular, tendiente a aumentar sus posibilidades de acceso al poder en una provincia con una hegemonía radical de 16 años consecutivos. La estrategia electoral puesta en práctica a fines de los noventa solo puede comprenderse analizando el campo político del tiempo inmediatamente anterior.

Derrotado en sucesivas elecciones (a la intendencia en 1983, a la gobernación en 1987, a la vicepresidencia por el PJ nacional en 1988 y, nuevamente, a la gobernación en 1991), De la Sota fue excluido de aspiraciones políticas importantes en la esfera federal y alejado de una nueva candidatura a nivel provincial en 1995. Ese año, junto con Angeloz, fue electo senador de la nación. Desde allí logró en poco tiempo ganarse el hasta entonces esquivo favor presidencial (De la Sota había perdido las internas justicialistas de 1988 con Menem).

En 1998, frente a una nueva recaída en la economía nacional y a las puertas de los comicios presidenciales, el menemismo se encontraba bajo asedio. En marzo, De la Sota presentó el proyecto más ambicioso de su carrera: la ley de convertibilidad fiscal. Se situó a partir de allí como uno de los principales defensores del 
modelo. Este debía ser perfeccionado pero no modificado tal como lo sostenía el ala del PJ liderada por Duhalde. La intensidad del apoyo del aparato presidencial a su candidatura a gobernador fue en este contexto inmensa. La razón de ello debe buscarse en el adelanto del calendario electoral. En efecto, Mestre, previendo para 1999 una pronunciada depresión en la economía cordobesa a causa de la crisis que Brasil estaba atravesando, fijó los comicios para octubre de 1998 (esto es, casi un año antes que en el resto del país).

Con la memoria aún fresca del "caso Angeloz", la reforma constitucional de 1994 expresamente prohibió una "re-reelección" presidencial. Aún así, Menem lo intentaría. El juez federal cordobés Bustos Fierro lo habilitó a estos efectos $^{14}$. De la Sota debía ser acompañado por Kammerath, secretario de comunicaciones de la nación y máximo referente local de la UCeDe, como candidato a vicegobernador. Nacía así la alianza partidaria Unión Por Córdoba (UPC).

El presidente puso a la nueva fórmula en contacto directo con los BMD durante la campaña misma. El 20 de diciembre de 1998, los candidatos de UPC obtuvieron el 49,59\% del total de los sufragios en tanto que Mestre-Avella alcanzaron el 40,47\%. Kammerath, perteneciente a un partido históricamente minoritario en la provincia, renunció a su cargo sin haberlo asumido. Con el apoyo de Menem-De la Sota ganó a Luís Juez la interna de UPC por la intendencia. El 10 de octubre de 1999, 14 días antes de los comicios presidenciales, repitió la hazaña derrotando a Negri por una diferencia de poco más de 7 puntos (UPC 42,47\% vs. 35\% UCR). Las autoridades electas asumieron el gobierno el 10 de diciembre de ese año y con ello una nueva etapa en lo que al neoliberalismo se refiere se inició en Córdoba ${ }^{15}$.

Desde Washington, el equipo del gobernador y los miembros de los BMD diseñaron lo que se dio a conocer como el "Estado nuevo". Este suponía un conjunto de reformas que, en términos generales, respetaba los ejes centrales del informe de la mencionada misión del BM del año 1995. El mayor punto de controversia giró en torno a la rebaja impositiva del $30 \%$ que De la Sota había anunciado durante su campaña en tanto se entendía podría socavar la recaudación fiscal. Las medidas propuestas fueron financiadas por sendos préstamos del BM y del BID por un monto de 303 y 215 millones de dólares, respectivamente ${ }^{16}$; préstamos que fueron otorgados a través de un procedimiento de contratación directa con la esfera provincial. El FMI, por su parte, envió a Córdoba una misión de asesoramiento técnico a fines de 1999 (Takagi, 2004, p. 54). La venia de la presidencia De la Rúa se concedió, finalmente, a cambio de la suscripción del Pacto fiscal n. ${ }^{\circ}$ III.

La cara del "Estado nuevo" en la ciudad de Córdoba estuvo representada por la ordenanza n. ${ }^{\circ} 10.207$ que se aprobó a instancias de Kammerath a principios del año 2000 (Ase, 2001). Este se trasladó a Río IV a través de la ordenanza local 'Río IV, nueva ciudad' y del convenio marco de cooperación intermunicipal firmado entre los intendentes de ambas capitales a estos efectos ${ }^{17}$.

En el resto de las localidades, el neoliberalismo fue canalizado a través del proceso de reforma impulsado por el "Pacto fiscal". Entre los antecedentes de este instrumento se destacaron sus homónimos a nivel nacional, el informe de la misión del BM de 1995, del FMI de 1999, de los créditos del BID y BM de 1999 y, finalmente, uno realizado por el instituto IERAL de la Fundación Mediterránea a solicitud del gobernador en el marco de los referidos préstamos. Estos dieron cuenta de una serie de deficiencias estructurales en la mayoría de las administraciones locales de finales del siglo $\mathrm{XX}^{18}$. La principal preocupación de la provincia giró en torno a la cuestión fiscal.

Esta se había deteriorado en los últimos años a partir de un fuerte nivel de endeudamiento de los gobiernos locales; deuda que a 1999 en su 
conjunto ascendía a los 480 millones de dólares y que en algunos casos había crecido en más del $100 \%$ en solo dos períodos presupuestarios ${ }^{19}$. Entre las causas de este fenómeno resaltaron, por un lado, la incapacidad de los municipios y comunas para sobrellevar las nuevas funciones que la descentralización les había encargado y, por otro, una caída del PBG provincial del 4,67\% y del PBI nacional del 3,38\% entre 1998 y $1999^{20}$.

El proceso de negociación del Pacto fiscal fue sumamente complejo, particularmente por la cantidad de actores involucrados y la amplitud de la reforma pretendida. Una de las principales medidas del oficialismo en este sentido fue la conformación de una institución con características verdaderamente novedosas: la Unidad Trabajo Provincia Municipio $(\mathrm{UTPM})^{21}$. En su seno se desempeñaban, de una parte, representantes de los ejecutivos locales divididos según los bloques políticos partidarios mayoritarios y de otra, funcionarios de la administración delasotista. En el caso concreto, la labor de la UTPM fue fundamental. Condensó en sus reuniones las interacciones más relevantes del proceso; mostró "la cocina" de las medidas que se iban adoptando y las redes de poder que se iban tejiendo alrededor y dentro del Estado subnacional.

El mecanismo fue eficiente y particularmente veloz. El pacto fue suscrito el 5 de febrero del 2000 (es decir un mes y medio después de la toma del poder) por 410 de los 428 gobiernos locales. No obstante ello, es relevante aclarar que entre las localidades que no lo ratificaron se registró un caso de enorme relevancia: el de la ciudad de Córdoba. Este hecho fue uno de los primeros síntomas y, a su vez, desencadenante del quiebre casi inmediato que sufrió la alianza entre De la Sota y Kammerath.

Difundido a la opinión pública, el proyecto del Estado nuevo a nivel provincial devino en centro de profundos debates. Principalmente lo apoyaron los representantes del partido ofi- cialista y los grandes capitales en sus diversos rubros (v. gr. bursátil, financiero, industrial y rural) simbolizados por la "Bolsa de comercio", la "Unión industrial", el "Concejo Federal de Inversiones", la "Confederación General Económica" y la "Sociedad rural"22. Entre los que lo resistieron se destacaron las cámaras de Pymes, los fuertes sindicatos de "Luz y fuerza" y de Empleados Públicos (SEP), la iglesia católica y el partido mayoritario de la oposición (v. gr. "la Alianza").

El debate se tradujo a la lógica política partidaria en el seno del poder legislativo. Hasta entonces, $\mathrm{y}$ al igual que sucediese a nivel local, el proceso de negociación con los BMD se había realizado íntegramente en el ámbito del ejecutivo. La instancia legislativa es fundamental en esta clase de procesos, sin embargo, supone altos costos en términos de transacciones entre partidos. En Córdoba esto último sería particularmente cierto. El gobernador presentó las reformas utilizando la técnica del "empaquetamiento", que consiste en aunar en un mismo proyecto legislativo un conjunto de políticas que pudieran/debieran ser tratadas por separado. En dicho paquete se incluyeron una serie de transformaciones - $\mathrm{v}$. gr Carta al ciudadano y privatización de la Lotería de Córdoba- que escapaban a las acordadas con los BMD, pero que se introdujeron como si así lo fuesen.

Si bien en la Cámara de diputados el oficialismo contaba con las mayorías requeridas para la aprobación del proyecto, no sucedía lo mismo en el Senado. Comenzó así un intrincado juego político para conseguirlas. Los esfuerzos se dirigieron a la captación de los senadores de la Alianza. Tras el tímido apoyo recibido desde el nivel nacional y recordando la experiencia de Menem-Alfonsín, De la Sota concertó con el exgobernador Mestre un acuerdo que se difundió como el "Pacto de las Tejas". Sin embargo, la UCR desconoció al exmandatario como legítimo interlocutor. El proyecto se aprobó finalmente con la compra del voto del senador Bodega $^{23}$. 


\section{Análisis del contenido de las reformas del Estado nuevo y del Pacto fiscal}

Las leyes n. ${ }^{\circ} 8.835 / 6 / 7$ y 8.864 fueron el equivalente provincial a las nacionales $n^{\circ}{ }^{\circ}$ 23.696/7 de 1989, base del modelo menemista; es decir, fueron sancionadas con la finalidad de efectuar una verdadera "reinvención del Estado cordobés ${ }^{24 "}$ siguiendo los presupuestos propios del neoliberalismo. A continuación, delineamos los rasgos centrales de su contenido:

a) Carta al ciudadano; ley provincial $n .^{\circ}$ 8.835: su articulado, que en términos generales era una copia de su homónima del Reino Unido, giró en torno al reconocimiento de los derechos que dan forma, en palabras de Villavicencio (2001), a la "nueva ciudadanía neoliberal". En efecto, el capítulo $1 .^{\circ}$ fijó los "derechos de las personas en su relación con el Estado", el capítulo $3 .^{\circ}$ estableció los "derechos y deberes de los usuarios de los servicios públicos" — creando oficinas para sus reclamos, fomentando su asociación e instituyendo los procesos de "audiencias públicas" - y, finalmente, el capítulo $5 .^{\circ}$ hizo lo propio con los de los "consumidores", dando forma a un nuevo "Sistema de arbitraje de consumo". Este reconocimiento se completó con la determinación de los "deberes del Estado provincial" (capítulo $2 .^{\circ}$ ). Los artículos 11 , 12 y 13 fijaron los estándares de evaluación de calidad a los que debería someterse la administración pública; estándares que buscaban la adaptación de esta a las normas internacionales sobre la materia (v. gr. normas ISO).

Tres institutos más dieron forma al contenido de la ley. En primer lugar, la norma creó el Ente Regulador de los Servicios Públicos (ERSEP), que tendría a su cargo, precisamente, la regulación de los servicios que se prestasen en el territorio provincial - artículo 22-. En segundo lugar, la ley conformó la "oficina anticorrupción", que sería "el organismo encargado de velar por la prevención e investigación de aquellas conductas que se considerasen comprendidas en la Convención Interamericana contra la
Corrupción —artículo 50-”. En tercer lugar, y vinculado a lo anterior, la norma constituyó el "Fuero penal económico y anticorrupción" en el ámbito de la $1 .^{\circ}$ circunscripción judicial de la provincia - artículo 53-. Se trataba de todos los institutos dirigidos a transparentar y diferenciar el proceso de reforma encarado de los mal llamados "errores de la privatización argentina" de principios de los noventa que tuvieron funestas consecuencias para el modelo de convertibilidad.

b) Ley provincial $n .^{\circ} 8.836$ de modernización del Estado: su corazón se ubicó en su título $2 .^{\circ}$. El capítulo $3 .^{\circ}$ de dicho título fijó las bases del ajuste estructural del gasto público. El artículo 7, en particular, señaló que la ley de presupuesto provincial estaría sujeta a las siguientes reglas: "equilibrio presupuestario", "déficit corriente cero" y "límite al crecimiento de la deuda pública" (el incremento de la deuda provincial no podría exceder el $1 \%$ del PBG para cada ejercicio fiscal). El ajuste se completó con las disposiciones del capítulo $5 .^{\circ}$. Estas buscaban minimizar y reestructurar el Estado, al mismo tiempo que concentraban a tales efectos enormes atribuciones en el ámbito del PE. En efecto, el artículo 17 lo facultó a elaborar un "Plan de reinvención del sector público provincial" y el artículo 20 le delegó la capacidad para: a) reformar, descentralizar, incorporar capitales privados, transferir, suprimir y/o liquidar los organismos de la administración pública; b) descentralizar, transferir, incorporar capital privado, desregular los "servicios, funciones u obras" cuya gestión se encontrase a cargo de los entes del Estado provincial. A tales fines, el artículo 21 lo habilitó a "intervenir" dichos organismos por el plazo de un año, prorrogable por igual período.

Un punto central de la reforma se ubicó en el recorte de la planta de personal del Estado. Con relación al mismo, la ley contempló las siguientes disposiciones: a) el artículo $26 \mathrm{fa}$ cultó a los PE, PL y PJ a "reasignar, transferir o reubicar" a sus empleados dentro o fuera de 
su competencia en tanto que el artículo 27 los autorizó "a gestionar, con entidades empresarias y/o sindicales" programas que facilitasen el desplazamiento de dichos empleados hacia la actividad privada; b) el artículo 28 estableció el régimen de "jubilación automática" de todos los agentes que hubiesen reunido los requisitos fijados por la normativa vigente para retirarse; c) el artículo 29 creó el instituto de "pasividad anticipada voluntaria" que permitía al personal del sector público acogerse al régimen de jubilación aún cuando le faltase entre 1 y 10 años para completar sus aportes jubilatorios; d) los artículos 30, 31 y 32 completaron el escenario a través de los regímenes de "transferencia de personal a la actividad privada", "retiro voluntario" y "prohibición de reingreso" a la administración pública.

El artículo 46 abrió el camino a la privatización de los "servicios públicos" al disponer que los mismos podrían ser prestados por agentes privados habilitados a estos efectos, mientras que el artículo 62 fomentó la de los "contratos de obras públicas" al disponer que, como regla general, toda obra pública sería efectuada en adelante incorporando capital privado. Finalmente, los artículos 97 y 98 buscaron la explotación de los corredores viales por medio de sujetos particulares (v. gr. "Peajes").

La ley se cerró con dos prescripciones destinadas a dar transparencia al proceso activado: a) el artículo 4 conformó una comisión cuyo objetivo principal sería el de controlar al PE en el ejercicio de las atribuciones conferidas; b) el artículo 10 creó el "Sistema de información pública" como parte central del nuevo "Estado cristalino ${ }^{25}$ ", que tendría "como función la publicidad de los actos de gobierno y de Estado y la difusión de toda información referida a la provincia que sea de interés...".

c) Incorporación del capital privado al sector público; ley provincial $n .^{\circ} 8.837$ : esta se dirigió a privatizar las principales empresas del Estado cordobés. En efecto, su artículo 4 facultó al PE “a proceder a la incorporación de capital privado - en forma total o parcial - o a la liquidación de empresas, sociedades, establecimientos o entidades cuya propiedad pertenezca, total o parcialmente al Estado provincial". Para instar el procedimiento de privatización o liquidación de una entidad pública, constituía un requisito previo e ineludible la declaración de la misma como "sujeta a incorporación de capital privado"; declaración que debía ser efectuada por el propio PE y remitida al PL, a los fines de su aprobación - artículo 5-. Ahora bien, el artículo 6 exceptuó de este requisito a aquellas entidades incluidas en la parte especial de la ley; esto es, expresamente incluidas en su título 3.

Este se subdividió en cuatro capítulos. El primero buscó la privatización de las actividades de "generación, distribución, transporte y comercialización de la energía eléctrica"; el segundo, la de la Empresa Provincial de Energía Eléctrica; el tercero, la del Banco de la Provincia de Córdoba; el cuarto, la de la Lotería de Córdoba. Es fundamental señalar que, a excepción de esta última, las restantes privatizaciones no pudieron concretarse por el escenario propio de la crisis del $2001^{26}$.

d) Pacto fiscal; ratificado por ley provincial $n .^{\circ}$ 8.864: el eje del Pacto giró en torno al "saneamiento fiscal" de estos últimos. A través del mismo, la provincia aceptaba la reprogramación de las deudas locales pendientes al 30 de noviembre de 1999 mediante los denominados "Títulos de apoyo municipal". Como contracara, las partes se comprometían a desistir de las acciones judiciales o administrativas en trámite y renunciaban en forma irrevocable a todo reclamo posterior.

No obstante ello, el contenido del Pacto no se limitó a estos aspectos. Entre sus medidas se destacaron la conformación del Fondo anticrisis y saneamiento municipal, la armonización tributaria y catastral a nivel provincial, la confección de un presupuesto desagregado de las cuentas locales y de un registro de las 
deudas municipales, la reforma de la LOM en lo atinente a retribuciones y la adopción de una serie de políticas tendientes a transparentar las gestiones locales. Para su aprobación, la gobernación recurrió nuevamente a la "estrategia del empaquetamiento". Esta vez, el "paquete" de políticas se ató en torno al refinanciamiento de las deudas locales.

Mención aparte merece: a) la creación de los "entes intermunicipales de recaudación fiscal y gestión" (título XIII) que, como su nombre lo indica, tendrían a su cargo la "tercerización" y "privatización" de los sistemas recaudatorios municipales-comunales que estarían en adelante a cargo de agentes privados especializados que actuarían en el seno de los mismos; b) el control que el Pacto habilitaba a realizar a la provincia sobre el gasto público de los gobiernos locales incluyendo el número de empleados por ellos designados (los gastos en planta de personal no podían sobrepasar el 50\% del presupuesto municipal-comunal).

\section{Reflexiones finales}

La penetración del neoliberalismo en Córdoba muestra la importancia de la variable "política partidaria" en esta clase de procesos y la activación de dos estrategias de difusión-imposición: los "Pactos fiscales" (indirecta) y las "misiones y créditos" de los BMD a las esferas subnacionales (directa). En tanto que en estas últimas su actuación sobre el ámbito a reformar es "directa", en la primera se encuentra mediada por una instancia estatal que ya ha adherido al modelo. Así el gobierno nacional, primero, y luego el provincial, se convirtieron simultáneamente en "objetos receptores" y "agentes promotores" de esta doctrina económica-social.

En los municipios y comunas de la provincia, el modelo se impuso de manera "indirecta" (Pacto fiscal) y aprovechando una situación de endeudamiento. Al igual que sucedió previamente a nivel nacional, el neoliberalismo - o su puesta en práctica- apareció como "causa y solución principal" de este fenómeno. En efecto, la deuda local se acrecentó significativamente en el marco del proceso recesivo que desde 1998 atravesaba el país y se generó, primordialmente, a partir de los procesos de descentralización instados por los BMD. Los informes de la fundación mediterránea, de la misión del BM de 1995 y del FMI de 1999 fueron los encargados de "diagnosticar, recetar y medir" la realidad cordobesa de acuerdo con una matriz analítica de corte neoliberal.

De igual modo, el proceso de gestación del Pacto aparece como la máxima expresión de la "nueva gobernanza neoliberal". Esta, cabe recordar, se presenta como un nuevo estilo de gobierno que pretende superar los fracasos de otros modos de gestión como la mano invisible del mercado o la planificación top-down del Estado a partir de "redes" flexibles de cooperación entre los distintos agentes involucrados en una misma política pública. El gobierno provincial, en el caso concreto, dejó de operar en términos jerárquicos y verticales (rompiendo con ello con la lógica de la planificación estatal top-down) para pasar a asumir un rol de "coordinador" de las relaciones de cooperación horizontal (que alteran la lógica del actor racional propia del mercado) existentes entre los gobiernos locales y que llevaron, en definitiva, a la suscripción del aludido Pacto.

El Derecho así creado impide pensar el fenómeno jurídico en los términos de las tradicionales categorías de hard and soft law. Esto es así porque en su nuevo rol, la entidad central (v. gr. el PE provincial) carece de los mecanismos jurídicos necesarios para coaccionar a los distintos agentes involucrados (v. gr. PE locales) en miras al cumplimiento efectivo de lo acordado. En Córdoba, esto se puso en evidencia en relación a la conformación de los entes regionales. El instrumento jurídico suscrito no brindó a la gobernación las herramientas requeridas para sancionar a las municipalidades y comunas retrasadas, pues eran ellas las que, a través de su cooperación y no a partir de la imposición jerárquica (v. gr. lógica top-down), debían agruparse 
en las nuevas entidades. La presión para que así lo hiciesen provino en el caso particular de la amenaza del PE provincial de cancelar el envío de los fondos propios del FAMASU; es decir, provino por fuera de los mecanismos brindados por el propio instrumento jurídico.

Sousa Santos (2007, p. 35) critica esta concepción, no porque considere que las nociones de 'coordinación' y 'cooperación' sean axiomáticamente negativas, sino porque en el neoliberalismo ellas están "al servicio de la concentración-polarización de recursos y de una democracia participativa pero selectiva...". Esto, lejos de ser una crítica meramente ideológica, deviene de los presupuestos de los que parte esta concepción. Se trata, en efecto, de modelos abstractos que carecen de una teoría estructural del poder y que son funcionales al mercado al establecer mecanismos institucionales de consenso (v. gr. UTPM) sin distribuir los capitales sociales existentes. En el Pacto, la cooperación no se generó "desde abajo" sino "desde arriba" y su núcleo giró en torno a las políticas de ajuste y privatización instadas por los BMD a nivel nacional.

El contenido de las reformas analizadas muestra la aparición de la segunda generación de reformas. En concreto, se delineó el contenido de la nueva ciudadanía neoliberal que tiene eje en los derechos y deberes de los consumidores y usuarios. Se buscó traer de nuevo el Estado al centro de la vida social a partir de la construcción de una administración institucionalmente eficiente. Se siguieron en este sentido principios del New Public Management que incorporan en el sector público criterios de calidad y lógicas de funcionamiento surgidos en el ámbito empresarial privado. Se reconoció a la sociedad civil y se fomentó la participación de ONG en el diseño y control de políticas públicas. Se creó el ERSEP con el objetivo inmediato de controlar los procesos de privatizaciones que la reforma misma activaba. La impronta del contexto nacional adquirió máxima expresión en estas leyes en la conformación de la Ofici- na anticorrupción y del Fuero penal económico y anticorrupción. Hacia finales de la década, y luego del menemismo, la corrupción se ubicaba en el centro mismo de los debates políticos. Estas medidas buscaron, consecuentemente, legitimar las transformaciones a implementar. Se intentó, asimismo y a través del Pacto fiscal, hacer eficientes las administraciones locales y regionalizar el territorio cordobés.

No obstante ello, debe decirse que todas estas políticas se subordinaron en este caso al núcleo básico del contenido del consenso de Washington; o dicho de otro modo, las reformas de segunda generación aparecieron en este proceso como subsidiarias y giraron en torno a las de primera generación. En efecto, el eje de la reforma se construyó en torno a un profundo ajuste estructural y a la privatización del Estado provincial, municipal y comunal. Resaltó, asimismo, la enorme concentración de facultades en el PE en detrimento de los PL de los dos niveles de gobierno.

\section{Notas}

${ }^{1}$ En Indonesia, por ejemplo, el FMI había concedido un paquete financiero a cambio de 140 condicionalidades que, dice Weisbrot (2002, p. 47), no había logrado más que asegurar el pago de la deuda externa y profundizar la recesión.

${ }^{2}$ Ver Weisbrot (2002, p. 3).

${ }^{3}$ Los datos expuestos son tomados de Manzo (2011, p. 271).

${ }^{4}$ Lardone (2006, p. 70 y ss).

${ }^{5}$ Entre otras, las teorías de la elección racional, de la acción pública, de las agencias, del actor racional, positiva, formal, de los juegos y de la acción colectiva (Friendland y Alford, 1999, p. 294).

6 V. gr. Friendland y Alford (1999); March y Olsen (1993) y Rothstein (2001). 
${ }^{7}$ Hood (1991, pp. 4-5) identifica siete componentes principales del NPM: "La incorporación de gerentes mánagers profesionales al sector público, los estándares para medir el desarrollo, el acento sobre el control por resultados, la desconcentración de unidades organizacionales, la incorporación de mecanismos de competencia al interior de la administración. La importación de prácticas del sector privado, y la mayor disciplina en el uso de los recursos...".

${ }^{8}$ V. gr. Díaz de Landa-Parmigiani de Barbará (1996); Cáceres (2006) y Cingolani (2006).

${ }^{9}$ Atlas electoral Andy Tow. Consultado el 10/10/11. Recuperado de http://towsa.com/ andy/totalpais/

${ }^{10}$ Atlas electoral Andy Tow. Consultado el 10/10/11. Recuperado de http://towsa.com/ andy/totalpais/

${ }^{11}$ Ver Lardone (2006, pp. 76-79).

12 Guía estadística de la municipalidad de Córdoba 2008. (Consultado el 10/10/11). Recuperado de http://www.cordoba.gov.ar/cordobaciudad/principal2/imagenes/Diseno/estadisticas.html

${ }^{13}$ Ver Díaz de Landa-Parmigiani de Barbará (1996) y Cingolani (2006).

${ }^{14}$ Diario Clarín (04/04/2000). Por esta decisión, se iniciaron acciones legales en contra del juez Bustos Fierro.

${ }^{15}$ Atlas electoral Andy Tow. (Consultado el 10/10/11). Recuperado de http://towsa.com/ andy/totalpais/

${ }^{16}$ Préstamo $\mathrm{N}^{\circ} 4.585$ del BM y préstamo $\mathrm{N}^{\circ} 1.287 / \mathrm{OC}-\mathrm{AR}$ del BID.

${ }^{17}$ El convenio se ratificó por la ordenanza $\mathrm{N}^{\circ}$ 187/00 del 25-07-00.
${ }^{18}$ Ver Parmigiani de Barbará (2002, p. 2).

${ }^{19}$ Datos suministrados por el presidente de la UTPM. Entrevista del 22 marzo de 2005.

${ }^{20}$ Guía estadística de la municipalidad de Córdoba 2008. (Consultado el 10/10/11). Recuperado de http://www.cordoba.gov.ar/cordobaciudad/principal2/imagenes/Diseno/estadisticas.html

${ }^{21}$ Resolución 132/99 del 24 de agosto de 1999 ratificada por el Pacto y la ley 8.864 .

${ }^{22}$ El apoyo fue emitido a partir del Acuerdo para la inversión y desarrollo firmado por las instituciones señaladas. Ver Boneto (en la bibliografía aparece bonetto, con 2 T), Martínez y Piñero (2003).

${ }^{23}$ El arrepentido Alfredo Alberto Norhún le contó al diario Clarín el jueves 27 de julio de 2000 cómo se pagaron los 400.000 dólares de coima al senador Bodega, quien fue expulsado del Bloque Frepasista y de la Unión de Tranviarios Automotor (UTA). Ver diario Ámbito Financiero del 03/08/00.

${ }^{24}$ Nombre del título $2 .^{\circ}$ de la ley 8.836 .

${ }^{25}$ Nombre del capítulo 4 del título 2..

${ }^{26}$ La crisis del neoliberalismo en Córdoba tuvo efectos desgarradores. Mientras que en la provincia el PBG descendió en el 2002 el $3,99 \%$ con respecto al año anterior, en la ciudad capital este descenso fue increíblemente del 24,42\% (de 8198 millones de pesos a 6195 millones). En octubre de 2002, el 28,2\% de las personas que habitaban el Gran Córdoba (capital y alrededores) se encontraban bajo la línea de la indigencia y el $58,5 \%$ bajo la de la pobreza. En mayo, el desempleo alcanzó el $25,3 \%$ de la PEA y el subempleo el $17,5 \%$. Guía estadística de la municipalidad de Córdoba 2008. (Consultado el 10/10/11). Recuperado de http://www.cordoba.gov.ar/cordobaciudad/ principal2/imagenes/Diseno/estadisticas.html 
El caso Córdoba: análisis de las leyes provinciales del Estado nUeVo y el Pacto fiscal

\section{Referencias}

Ase, I. (2001, 30 de agosto). La reinvención del Estado cordobés: una reingeniería de la ciudadanía. En Primer congreso nacional de administración pública, sociedad, gobierno y administración. Rosario, Argentina.

Bonetto, M. S., Martínez, F. y Piñero, M. T. (2003, 27 de noviembre). La construcción de la reforma del Estado en Córdoba: debates legislativos. En Segundo congreso nacional de administración pública: transición, instituciones y gobernabilidad. Córdoba, Argentina.

Burgos, G. (2000). El Banco Mundial y su análisis del derecho y el poder judicial. ¿De qué Estado de Derecho nos habla el Banco Mundial? 1992-1998. La mano invisible del mercado. Derecho y economía. El otro derecho, 24, agosto, pp. 47-95. Bogotá: ILSA.

Cáceres, P. (2006). La construcción sociopolítica de las regiones en la provincia de Córdoba. Políticas municipales para el desarrollo local y regional. Córdoba: EDUCC.

Cingolani, M. (2006). La descentralización de la salud en la provincia de Córdoba. Gobiernos bajo presión: relaciones intermunicipales y reforma del Estado: el caso Córdoba. Córdoba: EDUCC.

Díaz de Landa, M. y Parmigiani de Barbará, M. C. (1996). En lo pequeño y lo pobre... ¿Qué pasa con la salud?: un estudio sobre la descentralización en salud en comunas de la provincia de Córdoba. Córdoba: Alverony Ediciones.

Friendland, R. y Alford, R. (1999). Introduciendo de nuevo a la sociedad: símbolos, prácticas y contradicciones institucionales.
El nuevo institucionalismo en el análisis organizacional (pp. 294 a 329). Powell, W. y DiMaggio, P. (Comps.). México: Ed. Universidad Autónoma de Estado de México.

Hood, C. (1991). A Public Management for all Seasons? En Public Administration, 69, pp. 3-19. Spring.

Lardone, M. (2006). Bancos multilaterales de desarrollo y relaciones intergubernamentales en la reforma del Estado de la provincia de Córdoba. Gobiernos bajo presión: relaciones intermunicipales y reforma del Estado: el caso Córdoba. Córdoba: EDUCC.

Lardone, M. y Donadi, L. (2007). Construyendo consenso. La modernización del Estado y los mecanismos de articulación entre BMD y Think Tanks en Argentina. Fundación SIENA. (Consultado el 10/02/09) Recuperado de http://www.aaeap.org.ar/ejemplares_revista_apuntes_fundsiena.htm

Manzo, A. (2011). Derecho e institucionalización del neoliberalismo en Argentina: las reformas legales del período 1976-2002 (Tesis doctoral en Derecho y Ciencias Sociales) Universidad Nacional de Córdoba (UNC), directora: Martha Díaz de Landa, inédita.

March, J. G. y Olsen, J. P. (1993). El nuevo institucionalismo: factores organizativos de la vida política. Zona Abierta (pp. 1-43). Madrid: Ed. Pablo Iglesia.

Muñoz, R. A. (2007). Reforma política constitucional en Córdoba 1987. (Consultado el 08/02/09) Recuperado de http://www.saap. org.ar/esp/docs-congresos/congresos-saapVII/ programa/paneles/c/c9/munoz.pdf

Parmigiani de Barbará, C. (2002). Ponencia La coordinación intergubernamental subnacional 
de cara a la crisis: posibilidades y límites. Ponencia presentada en el Congreso del CLAD. Santo Domingo, República Dominicana.

Rapoport, M. (2010). Las politicas económicas de la Argentina. Una breve historia. Buenos Aires: ed. Booket.

Rothstein, B. (2001). Las instituciones políticas: una visión general. Nuevo manual de ciencia política, (pp. 199-238). Goodin, R. y Hans-Dieter, K. (comps.). Madrid: Ed. Istmo.

Sousa Santos, B. (2005). El milenio huérfano: ensayos para una nueva cultura política. Bogotá: Editorial Trotta/ILSA.

Sousa Santos, B. (2007). Más allá de la gobernanza neoliberal: el foro social mundial como legalidad y política cosmopolitas subalternas, en Sousa Santos y Rodríguez Garavito, El derecho y la globalización desde abajo: hacia una legalidad cosmopolita. México: Anthropos Editorial.

Takagi, S. et als. (2004). Informe sobre la evaluación del papel del FMI en Argentina, 1991-2001. Oficina de Evaluación Independiente del FMI, (consultado el 01/09/10) Recuperado de http://www.ieoimf.org/eval/complete/pdf/07292004/espanol.pdf

Villavicencio, S. (2001). Crisis de la ciudadanía: ¿nueva ciudadanía?, en Carozzi S. y Fitvo J. (comps.) (pp. 173-193). El desasosiego. Rosario: Ed. Homo Sapiens.

Weisbrot, M. (2002). Hearings before the Subcommittee on International Monetary Policy and Trade of the Committee on Financial Services U.S. House Of Representatives, Argentina's Economic Meltdown: Causes And Remedies. (Consultado el 01/09/10) Recuperado de http://financialservices.house.gov/media/pdf/107-52.pdf 